\title{
Research on Cause of Boron Steel Sheet Size Precision Based on Compensate Fuzzy Nerve Net Control
}

\author{
Zhanjun Liu \\ Faculty of Aerospace Engineering,Shenyang Aerospace University,China \\ Izjlzja@163.com
}

Keywords: drawing stress; emergency ratio; board deep; plastic modulus; subdued point

\begin{abstract}
The influence cause of boron steel sheet on size precision is studied, which is contained with additional drawing stress, emergency ratio, board deep, plastic modulus, subdued point, sclerotic index, crushing force, curvature radius and so on. In order to lay the further foundations of optimizing design, it is analyzed that the latent relation of influence cause of boron steel sheet on size precision by orthogonal experiment. The evaluation theory of influence cause of boron steel sheet is proposed . The evaluated equation on compensate fuzzy control is introduced into resistance affecting gene, the model of influence cause of boron steel sheet on compensate fuzzy control is built . The goal specimen is combined with the special predict results of affecting gene. It is showed that the affecting gene train is of correct or error define on compensate fuzzy control .
\end{abstract}

\section{Introduction}

A car rear cover drawing parts is for example, when the force of blank bigger, by tension and strain bigger than board surface strain yield, the quantity of stamping was decreased. the spring back quantity of blank after the plane strain state of the deformation is smaller than the spring back quantity of double drawing state after deformation.

The influence of the distribution deformation is bending radius of a sheet sizes When a sheet cover sizes is in rounded and other parts with bending deformation as the main deformation of the way, the smaller the bending radius, the greater plastic deformation, the smaller the spring back, the easier size accuracy improved. These factors are very complex, actual circumstances, the abstract expressions of sheet metal drawing force for:

$$
\begin{array}{ll}
\mathrm{P}=\mathrm{f}(\mathrm{h}, \mathrm{Q}, \mathrm{u}, \mathrm{n}, \mathrm{B}, \mathrm{r}) \\
\mathrm{In}: \quad h \text {-drawing stress; } \\
\\
\mathrm{Q} \text {-emergency ratio; } \\
\mathrm{u} \text {-friction coefficient; } \\
\mathrm{n} \text {-board deep; } \\
\mathrm{B} \text { - plastic modulus; } \\
\mathrm{r} \text { - subdued point; }
\end{array}
$$

Since type (1) of the most complex relationship, in fact, depends on the experimental research methods. In each factor to the deep impact force of plank, is based on experimental data sheet for the influence of the general rule of boron steel sheet, and its corresponding impact factor, regression method considering the impact factor value. But because of the boron steel sheet factor influencing the question belongs to a camera obscura or black cartridge with traditional methods, it causes there always consider interaction problems, or simply cannot consider a mutual influence, a mathematical model with actual situation, or a remote. Due to the complexity of the impact factor given, according to practical experience by experts, giving weighting factor compensation fuzzy neural network is to solve fuzzy reasoning optimization problem of the black box camera obscura or a good method[1] $\sim[4]$.

Compensation fuzzy neural network is a combination of fuzzy logic and neural network hybrid system, it is consistedof fuzzy neurons and decision-making for controlling, the fuzzy neuron are 
defined as fuzzy arithmetic and fuzzy reasoning, fuzzy arithmetic compensation and the blur operation. Networks can train from the initial definition of right or error definition of fuzzy rules, making the network higherfault tolerance, the system more stabling ${ }^{[2]}$. In compensation fuzzy neural networks, it is used in fuzzy operation dynamic and global optimization algorithm, and in the learning algorithm of neural network, fuzzy and dynamic optimization of the compensation arithmetic is made in the network of more adaptive and optimization. Network can not only adjust the input and output fuzzy membership function, but also can be compensated by means of dynamic optimization of adaptive fuzzy inference logic algorithm, the network parameters have clear physical meaning.

\section{Model Of Affect Gene Of Boron Steel Metal Sheet Built}

From (1), giving weighting factor $\mathrm{k}_{\mathrm{i}}$.

To: $\mathrm{P}=\mathrm{K}_{\mathrm{h}} \mathrm{K}_{\mathrm{Q}} \mathrm{K}_{\mathrm{u}} \mathrm{K}_{\mathrm{n}} \mathrm{K}_{\mathrm{B}} \mathrm{K}_{\mathrm{r}} \mathrm{P}_{0}$

In: $\mathrm{K}_{\mathrm{h}}$-weighting factor of boron steel of drawing stress;

$\mathrm{K}_{\mathrm{Q}}$ - weighting factor of boron steel of emergency ratio;

$\mathrm{K}_{\mathrm{u}}$-weighting factor of boron steel of friction coefficient;

$\mathrm{K}_{\mathrm{n}}$-weighting factor of boron steel of board deep;

$\mathrm{K}_{\mathrm{B}}$-weighting factor of boron steel of plastic modulus;

$\mathrm{K}_{\mathrm{r}}$ - weighting factor of boron steel of subdued point;

$\mathrm{P}_{0}$ - drawing force of based.

The overall evaluation reliable of metal plates boron steel factor influencing is defined as :

$\mathrm{A}=\lambda_{\mathrm{k}} * \mathrm{~N}$

$\lambda$ : reliable value, $0.9<\lambda<1$

Evaluation error value defined as:

$\mathrm{L}=|\mathrm{C}-\mathrm{A}| / \mathrm{C}<[\mathrm{L}]$

$\mathrm{C}$ :for test average;

$\mathrm{C}=\left(\sum \mathrm{n}_{\mathrm{p}} * \mathrm{~N}\right) / \mathrm{n} ; \mathrm{n}:$ for the test number。

[L] for the allowable value evaluation error in this experiment, take $[\mathrm{L}]=0.01$.

Testing precision level definition $\mathrm{D}=([\mathrm{L}]-\mathrm{L}) /[\mathrm{L}] * \mathrm{E}$

$\mathrm{E}$ is for user-defined level of accuracy, the coefficient of integer in the experiment, $\mathrm{E}=10$.

\section{Establishing Compensation Fuzzy Control System Of Sheet Metal Boron Steel Impact Factor}

The fuzzy optimization model of metal plates boron steel factor influencing is the key problem of system development ${ }^{[2]}$, and put all the sheet metal deep influence factor affecting factors of power for $\mathrm{U}=\left\{\mathrm{u}_{1}, \mathrm{u}_{2}, \ldots \mathrm{u}_{\mathrm{n}}\right\}$. Satisfy $\mathrm{U}=\mathrm{U}_{\mathrm{i}} \cup \mathrm{U}_{\mathrm{j}}$, and when $\mathrm{I}$ indicates whe $\mathrm{n} \mathrm{i} \neq \mathrm{j}, \mathrm{U}_{\mathrm{i}} \cap \mathrm{U}_{\mathrm{j}}=\{0\}$. The among vector of sheet metal deep influence factor affecting factors for $U=\left\{u_{i 1}, u_{i 2}, \ldots u_{i k}\right\}$. By introducing the weighted coefficient sets $A=\left(a_{1}, a_{2}, \ldots, a_{n}\right), a_{i}$ present level factors $u_{i}$, that is weight size.of $u_{i}$. All of the collection of various factors for $V=\left\{v_{1}, v_{2}, \ldots, v_{m}\right\}$ level set.

Based on the ideas above, for $\mathrm{r}_{\mathrm{ij}}\left(\mathrm{u}_{\mathrm{i}}, \mathrm{v}_{\mathrm{j}}\right)$.,it is introduced into dynamic variable $\mathrm{X}$ to improve, to build the fuzzy membership function of dynamic evaluation formula:of sheet metal boron steel factor influencing

$$
r_{i j}=\left\{\begin{array}{cl}
\mu_{i j}\left(u_{i}, \quad v_{j}, x\right), & \text { when parameters } x \text { impact conditions } \\
0, & \text { no composed by parameter condition of the influence } x
\end{array}\right.
$$

Type of dynamic variables, $\mathrm{x}$ is used to determine the different period of membership matrix. It is obtained the force of the sheet metal deep impact factor of the basic model of fuzzy dynamic evaluation. 


$$
\mathrm{B}=\mathrm{A} \circ \mathrm{R}=\mathrm{b}_{1} / \mathrm{v}_{1}+\mathrm{b}_{2} / \mathrm{v}_{2}+\ldots \mathrm{b}_{\mathrm{n}} / \mathrm{v}_{\mathrm{n}}
$$

" A $\circ$ R." is said "generalized fuzzy synthetic operation," To assess for vj grade of fuzzy subsets of membership, the fuzzy B vector normalization, according to the maximum membership degree, the result of dynamic testing can be got.

In this paper, the design of compensation fuzzy network evaluation of the sheet metal deep force impact factor, to choice of aluminum alloy plates deep deformation performance parameters as input node, with deep force factor influencing the plank as output node k. 6 input nodes is: contained with additional drawing stress, emergency ratio, board deep, plastic modulus, subdued point, sclerotic index.

Compensation fuzzy neural network structure has five layers: input layer, the blurred layer, compensation arithmetic, the blurred layer and output layer. It is based on fuzzy logic system between layer and layer of language variable and fuzzy if-then rules, the worst - the best operation, fuzzy reasoning method and the fuzzy functions. Among them, the each node of first layer is connected to the input vector directly; The each node of second layer represents a linguistic variable values, its role is to calculate the input vector belonging to each linguistic variable values of the fuzzy setting membership function; The each node of third layer represents a fuzzy rules, its role is to match the fuzzy rules, and calculates the suitable degree of each rule.

Fuzzy membership function for

$$
\begin{aligned}
& \mu_{A i}^{k}(x)=\exp \left[-\left(\frac{x_{i}-a_{i}^{k}}{\sigma_{i}^{k}}\right)^{2}\right] \\
& \mu_{B_{i}^{k}}(y)=\exp \left[-\left(\frac{y-b^{k}}{\delta^{k}}\right)^{2}\right]
\end{aligned}
$$

The alpha with sigma is for the center and width of inputting membership functions; B with the delta is as the center and width of the output membership function.

Define input $X=\left(x_{1}, \ldots, x_{n}\right)$, the theory of domain for: $U=U_{1} x U_{2} \ldots U_{n}, A$ ' is an input fuzzy subset of theory domain in $\mathrm{U}$, according to the fuzzy rules of $\mathrm{k}, \mathrm{B}$ ' is produced in the output field of $\mathrm{V}$ fuzzy subset, the fuzzy reasoning is used in the largest algebra product of synthesis arithmetic.

As a result, the system is made up of single valued fuzzy generator, gaussian membership function, the product of reasoning principle, negative - positive compensation algorithm and improved center of the compensation fuzzy neural networks.

In the design of sheet metal boron steel impact factor of compensation fuzzy network evaluation in the input node is selected of aluminum alloy sheet deep drawing deformation performance parameters, the output node is the $\mathrm{K}$ value of sheet deep drawing force impact factor. Six specific input nodes as follows: additional drawing stress, emergency ratio, board deep, plastic modulus, subdued point, sclerotic index[5].

\section{The Evaluating Examples Analysis Of Sheet Metal Boron Steel Impacting Factor On Compensation Fuzzy Neural Network}

Application of mathematical functions and software MATLAB fuzzy neural network, with compensation test sample see Tab.1, to train of evaluation results of a specific example sheet metal deep drawing force impact factor on compensation fuzzy neural network, in Tab.2. 
Tab.1 Data of test on compensate fuzzy control

\begin{tabular}{|c|c|c|c|}
\hline input nodes & test number 1 & test number 2 & test number 3 \\
\hline drawing stress & 10 & 20 & 30 \\
\hline board deep & 40 & 80 & 120 \\
\hline friction coefficient & 0.73 & 0.75 & 0.76 \\
\hline hardening exponent & 0.85 & 0.86 & 0.87 \\
\hline plastic modulus & 1.15 & 1.2 & 1.22 \\
\hline emergency ratio & 0.99 & 1.05 & 1.12 \\
\hline
\end{tabular}

Tab.2 Result of affect gene of boron steel on compensate fuzzy control

\begin{tabular}{|c|c|c|c|c|c|c|}
\hline $\begin{array}{c}\text { K gene } \\
\text { of } \\
\text { drawing } \\
\text { force }\end{array}$ & $\begin{array}{c}\text { Result of } \\
\text { control 1 }\end{array}$ & $\begin{array}{c}\text { Result of } \\
\text { control 2 }\end{array}$ & $\begin{array}{c}\text { Result of } \\
\text { control 3 }\end{array}$ & $\begin{array}{c}\text { K of test } \\
\text { average }\end{array}$ & $\begin{array}{c}\text { Most affect } \\
\text { gene of } \\
\text { experts }\end{array}$ & Error value \\
\hline $\mathrm{K}_{\mathrm{h}}$ & 1.535 & 1.540 & 1.545 & 1.540 & 1.454 & 0.003 \\
\hline $\mathrm{K}_{\mathrm{u}}$ & 1.770 & 1.776 & 1.779 & 1.775 & 1.772 & -0.002 \\
\hline $\mathrm{K}_{\mathrm{n}}$ & 1.658 & 1.659 & 1.657 & 1.658 & 1.654 & 0.003 \\
\hline $\mathrm{K}_{\mathrm{u}}$ & 1.861 & 1.865 & 1.866 & 1.864 & 1.865 & 0.002 \\
\hline $\mathrm{K}_{\mathrm{B}}$ & 1.880 & 1.884 & 1.885 & 1.883 & 1.881 & -0.003 \\
\hline $\mathrm{K}_{\mathrm{r}}$ & 1.791 & 1.794 & 1.687 & 1.684 & 1.681 & -0.002 \\
\hline
\end{tabular}

\section{Conclusion}

The influence cause of boron steel sheet on size precision is studied, which is contained with additional drawing stress, emergency ratio, board deep, plastic modulus, subdued point, sclerotic index, crushing force, curvature radius and so on .In order to lay the further foundations of optimizing design, it is analyzed that the latent relation of influence cause of boron steel sheet on size precision by orthogonal experiment. The evaluation theory of influence cause of boron steel sheet is proposed . The evaluated equation on compensate fuzzy control is introduced into resistance affecting gene, the model of influence cause of boron steel sheet on compensate fuzzy control is built . The goal specimen is combined with the special predict results of affecting gene. It is showed that the affecting gene train is of correct or error define on compensate fuzzy control .

\section{References}

[1] Zhao jun. Conical workpiece deep system in intelligent material parameters and the friction coefficient of on-line identification. Beijing: plastic engineering journal, 2001 (3) : 48-50.

[2] ZhaoZhenDuo . The friction and lubrication of metal plastic forming technology. Beijing: chemical industry press. 2004,9:50-53.

[3] WenWeiDong, Prediction model based on the fuzzy reliability . aircraft engine . In 2004, (3) : 322-323.

[4] LiuZhanJun. Difficulty reliability prediction research of titanium plate stamping forming based on the fuzzy control. Beijing: plastic engineering journal, 2005 (6) : 63-66.

[5]Wei ouyang, shangyu huang; The research and application of the electromagnetic forming technology [J];Journal of plastic engineering, 2005. 